\title{
Quantitative method to determine the regional drinking water odorant regulation goals based on odor sensitivity distribution: Illustrated using 2-MIB
}

\author{
Jianwei $\mathrm{Yu}^{1}$, Wei $\mathrm{An}^{1, *}$, Nan $\mathrm{Cao}^{2}$, Min Yang ${ }^{1, *}$, Junong $\mathrm{Gu}^{2}$, Dong Zhang ${ }^{3}$, Ning $\mathrm{Lu}^{3}$ \\ 1. State Key Laboratory of Environmental Aquatic Chemistry, Research Center for Eco-Environmental Sciences, Chinese Academy of Sciences, \\ Beijing 100085, China. E-mail: jwyu@rcees.ac.cn \\ 2. Beijing Waterworks (Group) Co. Ltd., Beijing 100085, China \\ 3. Shanghai National Engineering Research Center of Urban Water Resources Co., Ltd., Shanghai 200082, China
}

\section{A R T I C L E I N F O}

Article history:

Received 23 August 2013

Revised 22 November 2013

Accepted 10 December 2013

Available online 11 June 2014

Keywords:

Drinking water odor

Odor sensitivity distribution

Odor regulation goal

Flavor profile analysis

Odor episode

\begin{abstract}
A B S T R A C T
Taste and odor (T/O) in drinking water often cause consumer complaints and are thus regulated in many countries. However, people in different regions may exhibit different sensitivities toward T/O. This study proposed a method to determine the regional drinking water odorant regulation goals (ORGs) based on the odor sensitivity distribution of the local population. The distribution of odor sensitivity to 2-methylisoborneol (2-MIB) by the local population in Beijing, China was revealed by using a normal distribution function/model to describe the odor complaint response to a 2-MIB episode in 2005, and a 2-MIB concentration of $12.9 \mathrm{ng} / \mathrm{L}$ and FPA (flavor profile analysis) intensity of 2.5 was found to be the critical point to cause odor complaints. Thus the Beijing ORG for 2-MIB was determined to be $12.9 \mathrm{ng} / \mathrm{L}$. Based on the assumption that the local FPA panel can represent the local population in terms of sensitivity to odor, and that the critical FPA intensity causing odor complaints was 2.5 , this study tried to determine the ORGs for seven other cities of China by performing FPA tests using an FPA panel from the corresponding city. ORG values between 12.9 and $31.6 \mathrm{ng} / \mathrm{L}$ were determined, showing that a unified ORG may not be suitable for drinking water odor regulations. This study presents a novel approach for setting drinking water odor regulations. (C) 2014 The Research Center for Eco-Environmental Sciences, Chinese Academy of Sciences.
\end{abstract}

Published by Elsevier B.V.

\section{Introduction}

Odor in drinking water has long been a major cause of consumer complaints worldwide and is thus regulated in many countries (Yagi, 1988; Suffet et al., 1996; Bruchet, 1999; Yang et al., 2008; Yu et al., 2009; Proulx et al., 2012). In the USA, it is required that the threshold odor number be below 3 (US EPA, 2012; Wakayama, 2006), while in China, it is required that drinking water should be free from abnormal taste and odor (GB5749-2006). Japan shows a special concern for the two universally occurring cyanobacterial metabolites, trans-1,10-dimethyl-trans-9-decalol (geosmin) and 2-methylisoborneol (2-MIB) (Watson, 2004; Westerhoff et al., 2005; Li et al., 2012), requiring that the maximum contaminant levels (MCLs) for both should be below $10 \mathrm{ng} / \mathrm{L}$ (Wakayama, 2006). The same level was also used as the reference standard for the two odorants in China (GB5749-2006).

However, human responses to odorants are very complex. Individuals' sensitivity toward odorants has been found to be quite different. For example, the odor threshold concentration

\footnotetext{
* Corresponding authors. E-mail: anwei@rcees.ac.cn (Wei An); yangmin@rcees.ac.cn (Min Yang).
} 
(OTC) levels of geosmin and 2-MIB have been reported to range from 4 to $10 \mathrm{ng} / \mathrm{L}$ and 9 to $42 \mathrm{ng} / \mathrm{L}$, respectively (Pirbazari et al., 1993; Lloyd et al., 1998; Watson et al., 2000; Worley et al., 2003). At the same time, adaptation due to long-term exposure to a background odor in drinking water could lead to the loss of sensitivity to some odors (Dalton and Wysocki, 1996; Whelton and Dietrich, 2004). In addition, the masking effects of commonly used disinfectants on the odors of geosmin and 2-MIB have been extensively reported (Oestman et al., 2004; Curren et al., 2009), and increasing water temperature was found to increase the responses for these odorants (Whelton and Dietrich, 2004). Consuming cool water is very common in Japan, while drinking tea with hot water is normal in China. Thus the differences in water consumption habits could also impact the human sensitivity to the odorants. Furthermore, the presence of other odor-causing compounds through wastewater discharge or leakage from synthetic premise plumbing materials (Heim and Dietrich, 2007) may also interfere with the responses to these odorants. Thus, differences in odor sensitivity should exist among different regions with different social and environmental backgrounds (WHO, 2011), and Japan's MCLs for 2-MIB and geosmin may be too strict for some populations, while not sufficient for others. Therefore, it is desirable that each region should regulate drinking water odorants according to the sensitivity distribution of the local population.

At the present time, revealing the odor sensitivity distribution in a region is still a challenge, since normal people's responses to odorants are difficult to quantify, and there is no available approach to conduct such an investigation. In general, each person has a specific odor threshold (Doty et al., 1985; Schweitzer and Suffet, 1999; Devesa and Fabrellas, 2003; Mackey et al., 2004). In an odor episode, people may try to report a complaint when the odor level exceeds their odor threshold. Thus, it may be possible to reveal the odor sensitivity distribution of the local population in a region based on the daily odor complaint records. Based on this assumption, the 2-MIB sensitivity distribution of Beijing's population was acquired by using the complaint data in a 2-MIB odor episode in 2005. The 2-MIB odor regulation goal (ORG) was then derived for Beijing. The question is, how can one reveal the sensitivity distributions for other cities where the complaint data are not available?

Flavor profile analysis (FPA), which uses a minimum of four trained panelists to identify the types and intensities of the odors present in samples (APHA et al., 2005; Rashash et al., 1997), is one of the most popular drinking water odor sensory methods. FPA data can be described using the Weber-Fechner model to relate odor intensity to the logarithm of odorant concentration. In this study, eight groups of panelists from eight cities were formed, and each group on behalf of the local population of its own city was assigned to obtain a Weber-Fechner plot for 2-MIB. By matching the sensitivity distribution result derived from the complaint data with the Weber-Fechner plot acquired, it is possible to determine the critical FPA intensity causing odor complaints in Beijing's odor episode. By assuming that the critical FPA intensity causing odor complaint was the same for each city, the 2-MIB ORGs for the other cities could be obtained from their respective Weber-Fechner plots. This study can provide a valuable approach for odor regulation setting in the management of drinking water quality.

\section{Materials and methods}

\subsection{Diagram for determination of odorant regulation goals}

Fig. 1 shows the procedure for the determination of the ORG of a city, which mainly consists of two parts: acquiring the
Weber-Fechner plot of 2-MIB for each city, and deriving the odor sensitivity distribution of a city using the odor complaint data during an odor episode. This study tried to use the 2-MIB episode in Beijing in 2005 (Yu et al., 2009) as an example to illustrate the approach to reveal the odor sensitivity distribution of Beijing. By matching the sensitivity distribution result with the Weber-Fechner plot acquired for Beijing, the critical FPA intensity causing odor complaints was acquired. The 2-MIB concentration corresponding to this critical FPA value could be set as the ORG. By assuming that the critical FPA value is the same for the other cities, the ORGs for the other cities could be obtained from their respective Weber-Fechner plots.

\subsection{Odor evaluation}

FPA training and its applications are described in detail in the Standard Methods for the Examination of Water and Wastewater (APHA et al., 2005). In this study, eight panels from the drinking water quality monitoring centers of eight cities (Beijing, Wuxi, Hangzhou, Shijiazhuang, Haerbin, Zhengzhou, Shanghai and Kunming) were selected to perform the odor evaluation. Before performing odor evaluation, the panelists were initially given a centralized training for 4 days according to the FPA method. The training and odor evaluation were performed over a period of 5-25 Sep 2011. On the test days, the panelists were requested not to wear perfume, aftershave, hand lotion, or other substances. The samples were maintained at $45^{\circ} \mathrm{C}$ in a water bath, with at least one of them acting as a control consisting only of reagent water labeled "odor-free." Six concentrations of 2-MIB, including 15, 40, 80, 200, 400 and $600 \mathrm{ng} / \mathrm{L}$, were selected for FPA evaluations. Every panelist recorded the descriptor and the intensity of each sample, and each panel had its own average result. Then the Weber-Fechner plots of 2-MIB for each city were fitted using a linear function with $R$.

\subsection{2-MIB analysis}

2-MIB was analyzed using headspace solid-phase microextraction combined with gas chromatography/mass spectrometry (GC/MS) (Watson et al., 2000; Lin et al., 2002). Briefly, $50 \mathrm{~mL}$ water samples were placed into a $75 \mathrm{~mL}$ vial containing $12.5 \mathrm{~g}$ of desiccated $\mathrm{NaCl}$, with $10 \mathrm{ng} / \mathrm{L}$ 2-isopropyl-3-methoxy pyrazine added as the internal standard. Solid-phase microextraction fiber (No. 57348-U, Supelco, USA) was inserted into the headspace of the vial and maintained at $65^{\circ} \mathrm{C}$ for $30 \mathrm{~min}$. The GC/MS system included an HP 6890 GC with a $30 \mathrm{~m} \times 0.25 \mu \mathrm{m} \times 0.25 \mathrm{~mm}$ HP-5 MS capillary column and an HP 5973 mass spectrometer detector (Agilent, USA) and was operated in selective ion monitoring mode for quantification. The method detection limit for 2-MIB was $1 \mathrm{ng} / \mathrm{L}$.

\subsection{Odor complaint data source and analysis}

Data from a 2-MIB odor episode in Beijing in 2005, including the complaint telephone records for unpleasant odor and the 2-MIB concentrations in finished water, were used for this study (Yu et al., 2009, 2013). The daily complaint number is the cumulative number of sensitive population beyond a specific 


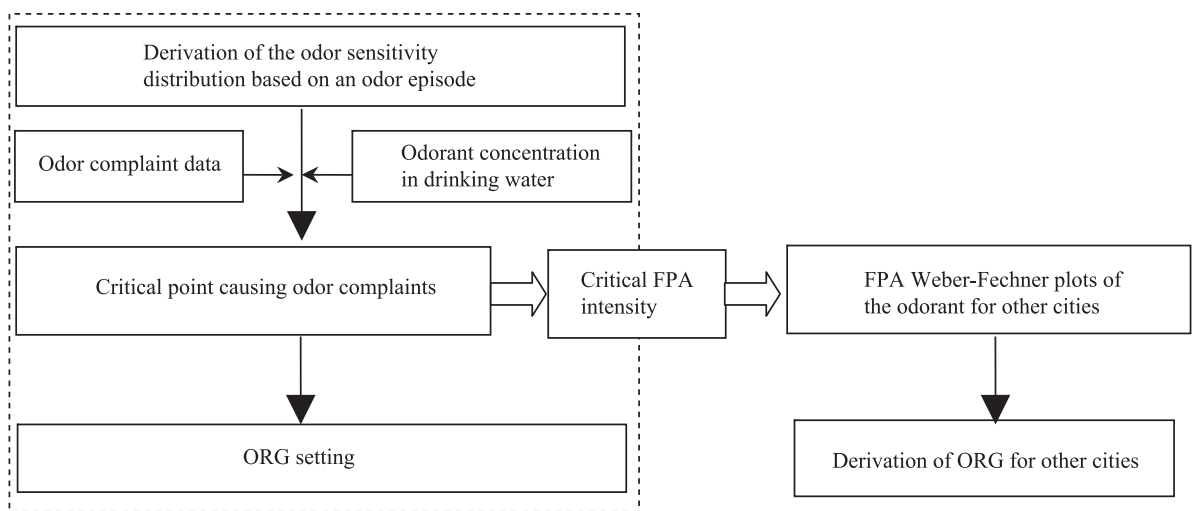

Fig. 1 - Diagram for determination of odorant regulation goals (ORG) based on odor sensitivity distribution.

threshold. These numbers form a sigmoid shape that can be characterized by the functions of the probit model (Yu et al., 2013), logistic model, normal cumulative distribution functions, etc. In this study, the normal cumulative distribution functions were chosen as a candidate for describing odor sensitivity distribution because the sigmoid shape is consistent with the differential sensitivity of individuals' odor thresholds, which was easily deduced as a normal probability function (Zajdlik, 2006).

The relation between the complaint proportion and the odorant concentration could be described as Eq. (1):

$p=\int_{0}^{x} \frac{1}{\sigma \sqrt{2 \pi}} \mathrm{e}^{\frac{(t-\mu)^{2}}{2 \sigma^{2}}} \mathrm{~d} t$

where, $x(n g / L)$ is the odorant concentration, and $p$ is the complaint proportion in the most sensitive population obtained by dividing the standardized complaint number by the maximum number. The $\mu(\mathrm{ng} / \mathrm{L})$ and $\sigma(\mathrm{ng} / \mathrm{L})$ are the mean and standard deviation, respectively, which characterize the sensitivity distribution of odor thresholds in population.

\section{Results and discussion}

\subsection{Weber-Fechner plots of 2-MIB}

The FPA experimental data of eight cities were fitted with the Weber-Fechner model, and compared with those performed by two USA laboratories, as shown in Fig. 2. OTC has been defined as the odorant concentration corresponding to an FPA intensity of 1 (Rashash et al., 1997; Suffet et al., 2004). Table 1 shows the corresponding OTC value of each city acquired using the Weber-Fechner model. It is clear that the panels from some cities including Beijing, Haerbin, Wuxi, etc., exhibited quite similar sensitivity to 2-MIB, with an OTC value of 7.1-12.0 ng/L. However, panels from Hangzhou and Zhengzhou exhibited much higher OTC values (13.1 ng/L and $18.2 \mathrm{ng} / \mathrm{L}$, respectively). The panel from Beijing exhibited the highest sensitivity to 2-MIB, which is understandable since the source water has been protected well, and no significant odor episode had been reported previously. The Hangzhou panel exhibited the lowest sensitivity, which may be due to the occurrence of adaptation, since a 2-MIB concentration of 10-20 ng/L seemed to be commonly present in the source water according to our previous investigation (Sun et al., 2013a,b). It is interesting, however, that the Shanghai panel was very sensitive to 2-MIB, although the drinking source water there suffered seasonal 2-MIB odor before the main source water was changed from the Huangpu River to Yangtze River at the end of 2010. One possible reason may be that the septic odor with an FPA intensity of 4-6 occurring over the whole year had interfered with the adaptation to the odor of 2-MIB (Sun et al., 2013a,b). In any case, the above result demonstrates that the sensitivities of local population in different cities to 2-MIB were quite different, and thus each city needs to determine its own ORG according to the sensitivity of the local population to odor.

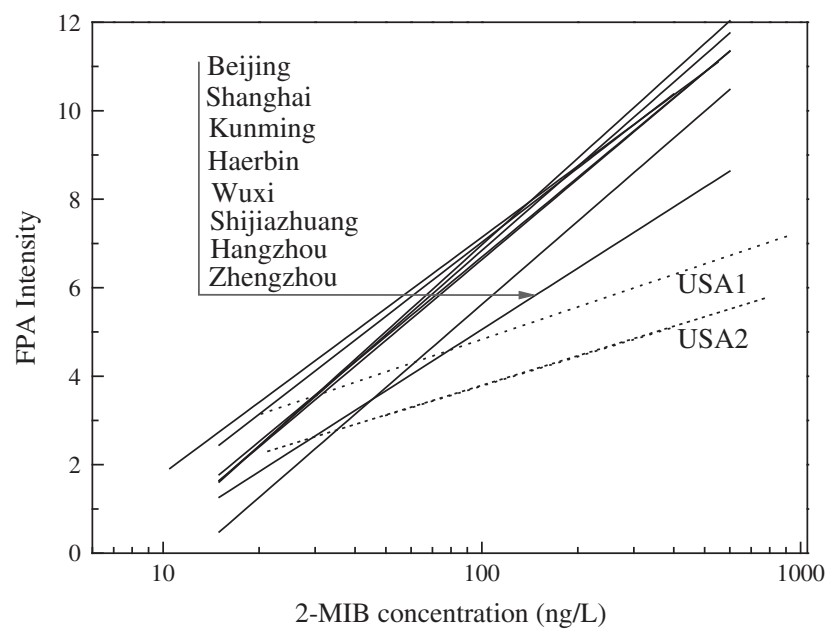

Fig. 2 - 2-MIB Weber-Fechner plots from FPA evaluation of eight cities (Beijing, Wuxi, Hangzhou, Shijiazhuang, Haerbin, Zhengzhou, Shanghai and Kunming) in China and two USA laboratories (USA1, USA2). 
Table 1 - Weber-Fechner model for the FPA rate intensity with 2-MIB concentration by the panels from different cities'

2-MIB concentrations corresponding to the FPA values of 1 and 2.5 was determined using the model, and was regarded as odor threshold concentration (OTC) and odor regulation goal (ORG).

\begin{tabular}{|c|c|c|c|}
\hline City & Weber-Fechner correlation & OTC (ng/L) & ORG (ng/L) \\
\hline Beijing & $\mathrm{FPA}=2.31 \mathrm{Ln}(\mathrm{MIB})-3.54 \mathrm{R}^{2}=0.97$ & 7.1 & 12.9 \\
\hline Shanghai & $\mathrm{FPA}=2.47 \mathrm{Ln}(\mathrm{MIB})-4.1 R^{2}=0.94$ & 7.9 & 14.5 \\
\hline Wuxi & $\mathrm{FPA}=2.59 \mathrm{Ln}(\mathrm{MIB})-5.25 R^{2}=0.98$ & 11.1 & 19.8 \\
\hline Shijiazhuang & $\mathrm{FPA}=2.63 \mathrm{Ln}(\mathrm{MIB})-5.48 R^{2}=0.99$ & 11.7 & 20.8 \\
\hline Haerbin & $\mathrm{FPA}=2.74 \mathrm{Ln}(\mathrm{MIB})-5.79 \mathrm{R}^{2}=0.99$ & 11.9 & 20.5 \\
\hline Kunming & $\mathrm{FPA}=2.83 \operatorname{Ln}(\mathrm{MIB})-6.05 R^{2}=0.98$ & 12.0 & 20.4 \\
\hline Zhengzhou & $\mathrm{FPA}=2.00 \mathrm{Ln}(\mathrm{MIB})-4.15 R^{2}=0.97$ & 13.1 & 27.9 \\
\hline Hangzhou & $\mathrm{FPA}=2.71 \mathrm{Ln}(\mathrm{MIB})-6.86 \mathrm{R}^{2}=0.99$ & 18.2 & 31.6 \\
\hline Mean & & 11.6 & 20.7 \\
\hline SD & & 2.0 & 4.0 \\
\hline $\mathrm{USA}^{\mathrm{a}}$ & $\mathrm{FPA}=1.06 \mathrm{Ln}(\mathrm{MIB})-0.04 R^{2}=0.78$ & 2.7 & 10.9 \\
\hline $\mathrm{USA}^{\mathrm{b}}$ & $\mathrm{FPA}=0.96 \operatorname{Ln}(\mathrm{MIB})-0.63 R^{2}=0.77$ & 5.5 & 26.4 \\
\hline
\end{tabular}

On the other hand, it was also noted that the slopes of the Weber-Fechner plots obtained in China (2.00-2.83) were significantly different from the two plots in the USA (around 1.0). They were significantly different using the Wilcox test method ( $\mathrm{W}=22, p=0.013$ ) as indicated with a normal $\mathrm{Q}-\mathrm{Q}$ plot in Fig. S1 (Appendix). However, the reason for such a difference in odor sensitivity needs further study.

\subsection{Derivation of the odor sensitivity distribution in Beijing based on complaint records}

In general, it is difficult to obtain the odor sensitivity distribution of a city due to lack of sufficient data for the odor response of a large population size. In this study, an odor episode (2-MIB) in Beijing was applied to illustrate the sensitivity analysis. The odor episode in drinking water

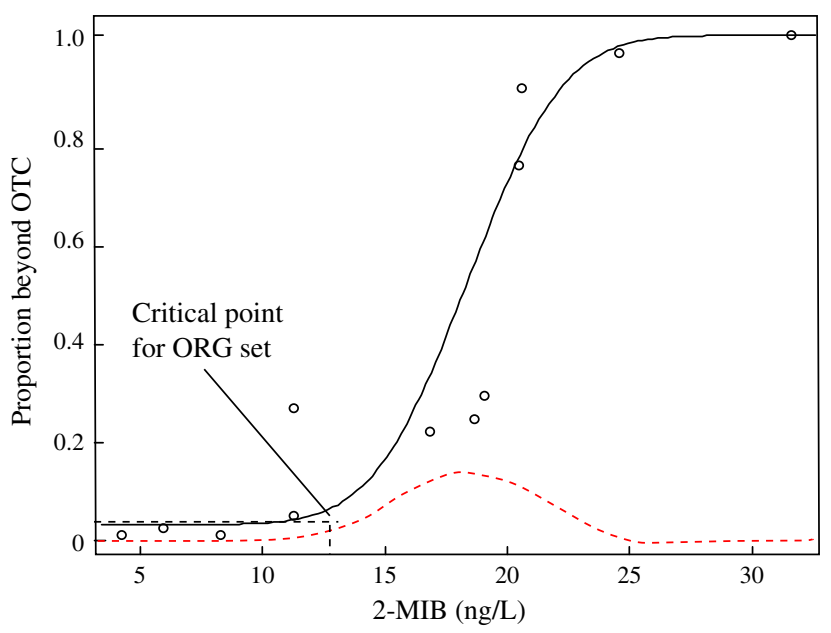

Fig. 3 - Odor complaint proportion change with 2-MIB increase (solid line) and the odor sensitivity distribution with 2-MIB concentration of the local population in Beijing (dashed line). continued for almost one month in Sep 2005. Fig. S2a shows the complaint records, with the highest complaint number recorded on Sep 17, 2005, when the highest 2-MIB concentration (32 ng/L) in drinking water was also recorded (Yu et al., 2009). By comparing the complaint records with the 2-MIB concentrations (Fig. 3), it was found that the number of complaints began to increase when the 2-MIB concentration in drinking water increased to above $10 \mathrm{ng} / \mathrm{L}$, which was close to the lower end of the OTC range (9 to $42 \mathrm{ng} / \mathrm{L}$ ) reported previously (Lloyd et al., 1998; Watson et al., 2000; Worley et al., 2003). While the concentration of 2-MIB in drinking water exceeded $20 \mathrm{ng} / \mathrm{L}$, the complaint number jumped to a level 4-5 times the background level, showing that the local people could not tolerate such a 2-MIB level.

In general, telephone complaints often occur during the same period. The hotline will not be available when all of the lines are occupied, meaning that not all of the complaints can be recorded; that is, the daily complaint numbers will not increase endlessly. The maximum daily complaint number was 81 for this odor episode in Beijing, which was used to transform the complaint number to a proportion ranging from of 0 to 1. Thus Eq. (1) was applied to regress the complaint response to 2-MIB in Beijing using $R$ as Eq. (2):

$$
p=\int_{0}^{x} \frac{1}{3.1 \sqrt{2 \pi}} \mathrm{e}^{\frac{(t-18.4)^{2}}{2 \times 3.1^{2}}} \mathrm{~d} t n=12, p<0.05
$$

Then the odor sensitivity probability distribution for the local population in Beijing was acquired as shown in Fig. 3, with the mean and SD at $18.4 \mathrm{ng} / \mathrm{L}$ and $3.1 \mathrm{ng} / \mathrm{L}$, respectively.

\subsection{Derivation of ORG based on odor complaint}

This study used the complaint record data in 2009, when no odor episode was reported, to determine the background complaint level of Beijing (Fig. S2b). Over the whole year, the probabilities of occurrence for daily complaint number exceeding 2 and 3 were $5.7 \%$ and $2.2 \%$, respectively. The statistically significant level of $<5 \%$ was used as the abnormal complaint level (Li et al., 2008; Merz et al., 2009), which 


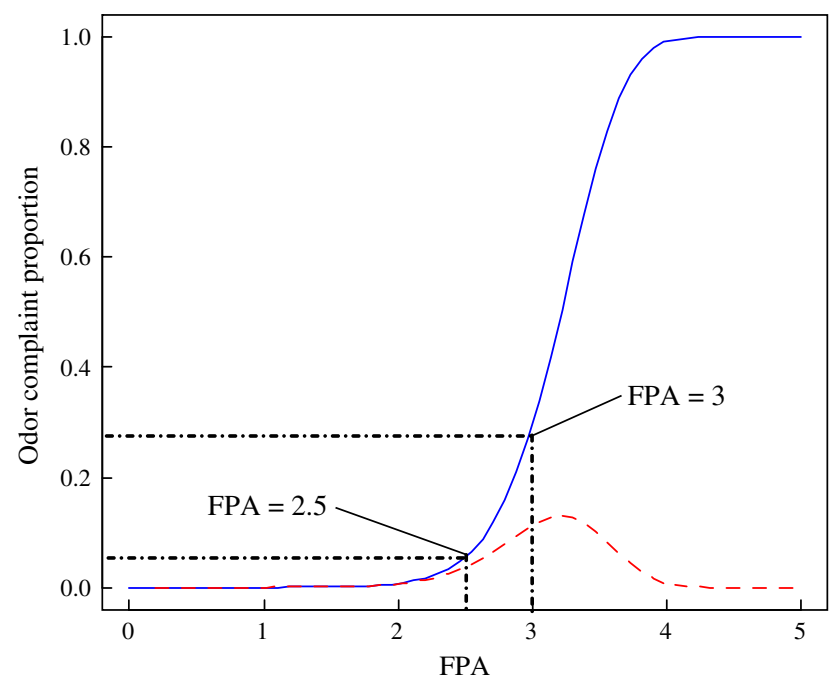

Fig. 4 - Odor complaint proportion change with FPA intensity increase (solid line) and odor-sensitive distribution with the FPA value of the local population in Beijing (dashed line).

corresponded to a daily number of complaint exceeding 3 for Beijing. Considering the fact that the maximum daily complaint number was 81 for the odor episode in 2005 in Beijing, the value of. $3.7 \%$ (i.e., 3/81) was adopted as the critical point for odor complaint response to 2-MIB. Corresponding to this critical point, the 2-MIB concentration was $12.9 \mathrm{ng} / \mathrm{L}$ (Fig. 3), and the FPA intensity was 2.5 (Fig. 4). Thus the ORG for Beijing could be set at $12.9 \mathrm{ng} / \mathrm{L}$.

By introducing the Weber-Fechner model of Beijing into Eq. (2), the relation between the FPA value and the complaint response level was further determined as shown in Eq. (3) and Fig. 4.

$p=\int_{0}^{\mathrm{FPA}} \frac{1}{7.16 \sqrt{2 \pi}} \mathrm{e}^{\frac{\left(e^{\frac{\mathrm{FPA}+3.54}{2.31}}-18.4\right)^{2}}{2 \times 3.1^{2}}+\frac{\mathrm{FPA}+3.54}{2.31} \mathrm{dFPA}}$

An FPA value of 3 was used as the odor control goal to trigger powdered activated carbon addition in some utilities (Suffet et al., 2004), at which point the corresponding complaint proportion is expected to rise to $30 \%$ in Beijing. Therefore, an FPA intensity of 2.5 was critical in protecting the sensitive population from suffering drinking water odor.

However, few cities could determine their ORG values using the above procedure due to lack of sufficient data for odor episodes. By assuming that the local FPA panel can represent the local population in terms of sensitivity to odor, this study tried to determine the ORG for each city through the FPA test using the local panel. Another assumption is that people will try to register a complaint when the FPA intensity of drinking water reaches a critical value, which was determined to be 2.5 as discussed above.

As shown in Table 1, the 2-MIB concentrations corresponding to the critical FPA intensity of 2.5 varied greatly, from $12.9 \mathrm{ng} / \mathrm{L}$ (Beijing) to $31.6 \mathrm{ng} / \mathrm{L}$ (Hangzhou). The above result demonstrates that the local populations in Hangzhou (ORG, $31.6 \mathrm{ng} / \mathrm{L}), \quad$ Zhengzhou (27.9 ng/L), Shijiazhuang (20.8 ng/L), Kunming (20.4 ng/L) and Wuxi (19.8 ng/L) were not as sensitive to 2-MIB. Although the detailed data are not available, the source waters of these five cities were mainly taken from lakes or reservoirs experiencing the problem of abnormal algal growth. In 2007, an extremely serious septic odor episode occurred in Wuxi, taking source water from Taihu Lake, leading to the suspension of water supply for several days. Although the major odorant was reported to be dimethyl trisulfide, 2-MIB was also reported (Yang et al., 2008). In addition, according to a taste and odor survey for 111 drinking water treatment plants in major cities across China (Sun et al., 2013a,b), 40\% of drinking water using source water from lakes or reservoirs had an earthy/musty odor, with an average 2-MIB concentration of $5.3 \mathrm{ng} / \mathrm{L}$, showing that the earthy/musty odor originating from 2-MIB occurs extensively in China's lake/reservoir source water.

As a matter of fact, the removal of 2-MIB through powdered activated carbon adsorption is much more difficult than that of geosmin (Craig et al., 1988; Cook et al., 2001). To reduce 2-MIB to a level below $10 \mathrm{ng} / \mathrm{L}$, as suggested by the MCL of Japan or the reference standard of China (10 ng/L), will increase the treatment cost significantly. Therefore, to ensure that the consumers will not suffer from drinking water odors and to control the odor abatement costs, it is desirable to set the ORGs according to the local population's sensitivity to 2-MIB.

\section{Conclusions}

The following conclusions were drawn based on the results of this study: (1) The FPA results demonstrated that the panels from the eight cities had different sensitivities to 2-MIB odor in drinking water, with an OTC value varying from 7.1 to $18.2 \mathrm{ng} / \mathrm{L}$. (2) The odor sensitivity distribution of the Beijing native population to 2-MIB was characterized by the normal function ( $\mu=18.4, \sigma=3.1$ ) using an odor episode in 2005, and a 2-MIB concentration of $12.9 \mathrm{ng} / \mathrm{L}$ and FPA intensity of 2.5 was found to be the critical point to cause odor complaint. The Beijing ORG for 2-MIB was thus determined to be $12.9 \mathrm{ng} / \mathrm{L}$. (3) Based on the assumption that the local FPA panel can represent the native population in terms of sensitivity to odor, and that the critical FPA intensity causing odor complaint was 2.5, the ORGs for seven other cities of China were derived from their respective Weber-Fechner plots. The ORGs for the eight cities varied greatly, from 12.9 to $31.6 \mathrm{ng} / \mathrm{L}$, suggesting that a unified standard for 2-MIB may not be suitable.

\section{Acknowledgments}

This work was supported by the National Natural Science Foundation of China (No. 21377144, 50938007,), the Funds for Major Science and Technology Program for Water Pollution Control and Treatment (No. 2012ZX07403-002-02), and the Key Scientific and Technological Projects of Science and Technology Commission of Shanghai Municipality (No. 12231201600). The authors would also like to thank all the FPA panelists from water quality monitoring centers including Kunming, Zhengzhou, Haerbin, Shijiazhuang, Hangzhou, Wuxi, Beijing and Shanghai, for their FPA evaluation support. 


\section{Appendix A. Supplementary data}

Supplementary data to this article can be found online at http://dx.doi.org/10.1016/j.jes.2014.05.003.

\section{R E F E R E N C E S}

APHA, AWWA, WEF, 2005. In: Eaton, A.D., Clesceri, L.S., Rice, E.W. et al. (Eds.), Standard Methods for the Examination of Water and Wastewater, 21st ed. American Public Health Association, Washington DC, USA.

Bruchet, A., 1999. Solved and unsolved cases of taste and odor episodes in the files of inspector Cluzeau. Water Sci. Technol. 40 (6), 15-21.

Cook, D., Newcombe, G., Sztajnbok, P., 2001. The application of powdered activated carbon for MIB and geosmin removal: predicting PAC doses in four raw waters. Water Res. 35 (5), 1325-1333.

Craig, S.L., Pirbazari, M., Dale, M.S., Tanaka, T.S., McGuire, M.J., 1988. Optimizing the removal of geosmin and 2-methylisoborneol by powdered activated carbon. J. Am. Water Works Assoc. 80 (3), 73-80.

Curren, J., Wang, L.P., Matud, J., Mackey, E.D., Suffet, I.H., 2009. The effect of water source and chlorine and chloramine odorants in drinking water on earthy and musty odour intensity. J. Water Supply Res. 58 (8), 521-531.

Dalton, P., Wysocki, C.J., 1996. The nature and duration of adaptation following long-term odor exposure. Percept. Psychophys. 58 (5), 781-792.

Devesa, R., Fabrellas, C., 2003. Sensorial analysis applied to drinking water. Alimentaria 40 (343), 59-63.

Doty, R.L., Applebaum, S., Zusho, H., Settle, R.G., 1985. Sex differences in odor identification ability: a cross-cultural analysis. Neuropsychologia 23 (5), 667-672.

Heim, T.H., Dietrich, A.M., 2007. Sensory aspects and water quality impacts of chlorinated and chloraminated drinking water in contact with HDPE and cPVC pipe. Water Res. 41 (4), 757-764

Li, H., Apostolakis, G.E., Gifun, J., VanSchalkwyk, W., Leite, S., Barber, D., 2008. Ranking the risks from multiple hazards in a small community. Risk Anal. 29 (3), 438-456.

Li, L., Gao, N.Y., Deng, J., Yao, J., Zhang, K.J., 2012. Characterization of intracellular \& extracellular algae organic matters (AOM) of Microcystic aeruginosa and formation of AOM-associated disinfection byproducts and odor \& taste compounds. Water Res. 46 (4), 1233-1240.

Lin, T.F., Wong, J.Y., Kao, H.P., 2002. Correlation of musty odor and 2-MIB in two drinking water treatment plants in south Taiwan. Sci. Total Environ. 289 (1-3), 225-235.

Lloyd, S.W., Lea, J.M., Zimba, P.V., Grimm, C.C., 1998. Rapid analysis of geosmin and 2-methylisoborneol in water using solid phase micro extraction procedures. Water Res. 32, 2140-2146.

Mackey, E.D., Baribeau, H., Crozes, G.F., Suffet, I.H., Piriou, P., 2004. Public thresholds for chlorinous flavors in US tap water. Water Sci. Technol. 49 (9), 335-340.

Merz, B., Elmer, F., Thieken, A.H., 2009. Significance of "high probability/low damage" versus "low probability/high damage" flood events. Nat. Hazards Earth Syst. 9 (3), 1033-1046.

Oestman, E., Schweitzer, L., Tombouli, P., Corado, A., Suffet, I.H., 2004. Effects of chlorine and chloramines on earthy and musty odors in drinking water. Water Sci. Technol. 49 (9), 153-159.

Pirbazari, M., Ravindran, V., Badriyha, B.N., Craig, S., McGuire, M.J., 1993. GAC adsorber design protocol for the removal of off-flavors. Water Res. 27 (7), 1153-1166.
Proulx, F., Rodriguez, M.J., Sérodes, J.B., Bouchard, C., 2012. Spatio-temporal variability of tastes and odors of drinking water within a distribution system. J. Environ. Manag. 105, 12-20.

Rashash, D.M.C., Dietrich, A.M., Hoehn, R.C., 1997. FPA of selected odorous compounds. J. Am. Water Works Assoc. 89 (4), 131-141.

Schweitzer, L., Suffet, I.H., 1999. Exposure assessment of taste and odor standards used in the method of flavor profile analysis. Water Sci. Technol. 40 (6), 209-215.

Suffet, I.H., Corado, A., Chou, D., McGuire, M.J., Butterworth, S., 1996. AWWA taste and odor survey. J. Am. Water Works Assoc. 88 (4), 168-180.

Suffet, I.H., Schweitze, L., Khiari, D., 2004. Olfactory and chemical analysis of taste and odor episodes in drinking water supplies. Rev. Environ. Sci. Biotechnol. 3 (1), 3-13.

Sun, D.L., Yu, J.W., Yang, M., An, W., Zhao, Y.Y., Lu, N., et al., 2013a. Occurrence of odor problems in drinking water of major cities across China. Front. Environ. Sci. Eng. http://dx.doi.org/10. 1007/s11783-013-0577-1.

Sun, D.L., Yu, J.W., An, W., Yang, M., Chen, G.G., Zhang, S.J., 2013 b. Identification of causative compounds and microorganisms for musty odor occurrence in the Huangpu River, China. J. Environ. Sci. 25 (3), 460-465.

US EPA, 2012. Secondary Drinking Water Regulations: Guidance for Nuisance Chemicals. vol. 816-F-10-079.

Wakayama, H., 2006. Revision of Drinking Water Quality Standards in Japan. Health Service Bureau, Ministry of Health, Labour and Welfare, p. 16.

Watson, S.B., 2004. Aquatic taste and odor: a primary signal of drinking-water integrity. J. Toxicol. Environ. Health A 67 (20-22), 1779-1795.

Watson, S.B., Brownlee, B., Satchwill, T., Hargesheimer, E.E., 2000. Quantitative analysis of trace levels of geosmin and MIB in source and drinking water using headspace SPME. Water Res. 34 (10), 2818-2828.

Westerhoff, P., Rodriguez-Hernandez, M., Baker, L., Sommerfeld, M., 2005. Seasonal occurrence and degradation of 2-methylisoborneol in water supply reservoirs. Water Res. 39 (20), 4899-4912.

Whelton, A.J., Dietrich, A.M., 2004. Relationship between intensity, concentration, and temperature for drinking water odorants. Water Res. 38 (6), 1604-1614.

WHO (World Health Organization), 2011. Guidelines for Drinking-Water Quality. World Health Organization, Geneva, Switzerland.

Worley, J.L., Dietrich, A.M., Hoehn, R.C., 2003. Dechlorination techniques to improve sensory odor testing of geosmin and 2-MIB. J. Am. Water Works Assoc. 95 (3), 109-117.

Yagi, M., 1988. Musty odor problems in lake Biwa: 1982-1987. Water Sci. Technol. 20 (8-9), 133-142.

Yang, M., Yu, J.W., Li, Z.L., Guo, Z.H., Burch, M., Lin, T.F., 2008. Taihu lake not to blame for Wuxi's woes. Science 319 (5860), 158.

Yu, J.W., Zhao, Y.M., Yang, M., Lin, T.F., Guo, Z.H., Li, S., et al., 2009. Occurrence of odour-causing compounds in different source waters of China. J. Water Supply Res. Technol. 58 (8), 587-594.

Yu, J.W., An, W., Yang, M., Gu, J.N., Cao, N., Chen, Y.J., 2013. Quick response to 2-MIB episodes based on native population odor sensitivity evaluation. Clean Soil Air Water. http://dx.doi.org/ 10.1002/clen.201200716.

Zajdlik, B.A., 2006. Potential statistical models for describing species sensitivity distributions. Prepared for the Canadian Council of Ministers of the Environment, January 2006. 